\title{
Caffeic acid decomposition products: antioxidants or pro-oxidants?
}

Susana Andueza ${ }^{\mathrm{a}}$, Lara Manzocco ${ }^{\mathrm{b}}$, M. Paz de Peña ${ }^{\mathrm{a}}$, Concepción Cid ${ }^{\mathrm{a},{ }^{*}}$ and Cristina Nicoli ${ }^{\mathrm{b}}$

${ }^{a}$ Departament of Nutrition, Food Science, Physiology and Toxicology, School of Pharmacy, University of Navarra, E-31080 Pamplona, Spain

${ }^{\mathrm{b}}$ Dipartimento di Scienze degli Alimenti, Università degli Studi di Udine, Via Marangoni 97, 33100 Udine, Italy

\section{Published in Food Research International 42 (1), 51-55 (2009)}

Corresponding author: Concepción Cid. Phone: +34 948425600 (Ext. 6264). Fax: +34948 425649. E-mail: ccid@unav.es 


\begin{abstract}
The potential of phenol antioxidants to suffer decomposition reactions leading to the formation of products exerting pro-oxidant activity was studied. A hydroalcoholic solution containing caffeic acid was assessed for antioxidant and pro-oxidant activity during heating at $90^{\circ} \mathrm{C}$ to simulate the heat maintenance of the coffee brews in thermos. Decomposition products were also evaluated by HPLC analysis. In the early steps of caffeic acid decomposition, a decrease in antioxidant capacity was detected, associated to a significant increase in prooxidant activity because the development of pro-oxidant compounds. On further heating, an increase in antioxidant activity associated to a decrease in pro-oxidant molecules previously formed and the formation of polymers with higher antioxidant activity was observed. A mechanistic route of caffeic acid decomposition under thermal conditions according to the HPLC analysis was proposed. This study clearly showed that caffeic acid, a well known antioxidant, may also act as pro-oxidant due to thermal decomposition.
\end{abstract}

\title{
KEYWORDS
}

pro-oxidant, antioxidant, caffeic acid, heat treatment 


\section{INTRODUCTION}

Plant polyphenolic have been shown to act as strong antioxidants in various systems and their multiple biological actions have been extensively reviewed (Meskin, Bidlack, Davies, Lewis and Randolph, 2004; Shahidi and Naczk, 2004). It is widely believed that polyphenols help maintaining human health by decreasing oxidative damage to key biomolecules. This result is supported by a number of cell culture studies examining the mechanisms behind oxidative stress prevention by polyphenols. However, recent evidences on the effect of flavonoids and other phenols in culture indicate the potential for artefact involving interactions of polyphenols with components of the cell culture media (Halliwell, 2003). In the light of these findings, it has been suggested that the major benefits of including dietary polyphenols in the meal can be related to their ability to reduce the generation of lipid hydroperoxides in the gastric fluid during digestion (Kanner \& Lapidot, 2001; Halliwell, 2003). Dietary polyphenols would thus prevent lipid peroxidation not only in the meal, but also in the stomach. However, the enthusiasm based on the awareness that polyphenols exert powerful antioxidant activities is now followed by a growing concern about their possible pro-oxidant effects. In fact, it is noteworthy that polyphenols are easily autoxidisable and able to reduce transition metal ions (Stadler, 2001; Halliwell, 2003). In addition, upon oxidation they easily beget decomposition products which might be pro-oxidants. For instance, it is known that phenoxy radicals or phenoxonium cations are involved in the oxidative polymerisation of phenols (Fulcrand, Benabdeljalil, Rigaud, Cheynier \& Mountounet, 1998; Kobayashi \& Higashimura, 2003). In addition, carbocation intermediates are expected to be produced from their cleavage at high temperature (Britt, Buchanan, Thomas \& Lee, 1995). 
For this reason, it is likely that molecules with pro-oxidant activity could be formed as a consequence of food processing operations promoting phenol polymerisation and/or degradation (e.g. food formulation, thermal treatment, dehydration, storage) (Nicoli, Calligaris \& Manzocco, 2000; Pinelo, Manzocco, Nunez \& Nicoli, 2004). In other words, reactions occurring during processing may invert dietary polyphenols from antioxidants to pro-oxidants and consequently favour lipid peroxidation and other oxidative reactions.

Although it is possible to find in the literature abundant studies about the antioxidant behaviour of phenol compounds, only few works are focused on the occurrence of pro-oxidant activity as a consequence of their thermal decomposition (Stadler, Welti, Stämpfli, \& Fay, 1996; Guillot, Malnoë \& Stadler, 1996; Stadler, 2001). Indeed, the development of pro-oxidant activity is hardly predictable on the basis of the antioxidant activity of the original phenolic compound.

On the basis of these considerations, the aim of this work was to evaluate the potential of polyphenols with recognised antioxidant activity to suffer decomposition reactions leading to the formation of products exerting pro-oxidant activity. Caffeic acid was chosen as an example of hydroxycinamic acid, which mainly contributes to dietary polyphenols being commonly assumed through coffee beverages (Rice-Evans, Miller \& Paganga 1996; Clifford, 1999). Since full characterisation of caffeic acid decomposition reactions has not been achieved yet, model solutions constituted a simplified medium for their preliminary exploration. The works of Stadler and coworkers were focused on the pyrolisis of caffeic acid to simulate the roasting process of coffee. However, the heat maintenance of coffee brews in thermos (i.e. in a catering, or in the office) during hours is becoming more common to have a hot coffee brew at once. For this reason, a 
hydroalcoholic model system containing caffeic acid was allowed to react at $90^{\circ} \mathrm{C}$ for increasing time and assessed for antioxidant and pro-oxidant properties. The hydroalcoholic solution was selected to simulate the aqueous medium with the presence of organic compounds of the coffee brew. The antioxidant activity was analysed by means of chain breaking activity and redox potential whilst prooxidant activity was evaluated by a spectrophotometric method. Possible attribution of pro-oxidant or antioxidant activity to specific caffeic acid decomposition products detected by HPLC analysis was also discussed.

\section{MATERIALS AND METHODS}

Chemicals and reagents. The methanol used was of spectrophotometric grade from Panreac (Barcelona, Spain)._Pure reference standards of caffeic acid and 2,2diphenyl-1-picrylhydrazyl (DPPH) were obtained from Aldrich (Steinheim, Germany) and catechol was purchased from Acros Organics (Springfield, New Jersey, USA).

Sample preparation. A solution containing $1 \% \mathrm{w} / \mathrm{v}$ of caffeic acid in ethanolwater $(1: 4)$ was prepared. The $\mathrm{pH}$ of the solution was adjusted at 4.6 by addition of $10 \mathrm{~N}$ sodium hydroxide to simulate coffee brew $\mathrm{pH}$. Aliquots of $10 \mathrm{~mL}$ of the solution were placed in $20 \mathrm{~mL}$ capacity vials which were hermetically closed with butyl septa and metal caps. Samples were heated at $90^{\circ} \mathrm{C}$ in an air circulating oven for increasing time up to 24 hours. After heat treatment samples were immediately cooled to room temperature in a water bath. Two independent experiments were evaluated.

Colour. Colour analyses were carried out using a tristimulus colorimeter (Chromameter-2 Reflectance, Minolta, Osaka, Japan) equipped with a CR-200 measuring head. The instrument was standardised against a white tile before 
measurements. Colour was expressed in $L^{*} a^{*}$ and $b^{*}$ Hunter scale parameters (Clydesdale, 1978).

Optical Density measurement. Samples were diluted with deionised water in order to obtain absorbance in scale. The absorbance at 280 and $420 \mathrm{~nm}$ was measured by a UVIKON 860 (Kontron Instruments, Milan, Italy) spectrophotometer.

Chain-Breaking Activity. The chain breaking activity was measured following the methodology described by Brand-Wiliams, Cuvelier and Berset (1995). In particular, the bleaching rate of a stable free radical, 2,2-diphenyl-1picrylhydrazyl (DPPH·), was monitored at a characteristic wavelength in the presence of the sample. In its radical form, DPPH· absorbs at $515 \mathrm{~nm}$, but upon reduction by an antioxidant or a radical species its absorption decreases.

A volume of $1.85 \mathrm{~mL}$ of $6.1 \times 10^{-5} \mathrm{M} \mathrm{DPPH} \cdot$ methanol solution was used. The reaction was started by adding $20 \mu \mathrm{L}$ of each sample. After mixing, the absorbance was measured at $515 \mathrm{~nm}$ after exactly $1 \mathrm{~min}$, and then every minute for $18 \mathrm{~min}$ (end reaction time). In all cases, the DPPH· bleaching rate was proportional to the sample concentration added to the medium. Reaction rates were calculated using the equation proposed by Manzocco, Anese and Nicoli. (1998):

$1 / \mathrm{Abs}^{3}-1 / \mathrm{Abs}_{\mathrm{o}}{ }^{3}=-3 \mathrm{kt}$

where $\mathrm{k}$ is the DPPH·bleaching rate, $\mathrm{Abs}_{\mathrm{o}}$ is the initial absorbance value and $\mathrm{Abs}$ is the absorbance at increasing time t. The chain-breaking activity was expressed as the slope obtained from the equation $\left(-\mathrm{Abs}^{-3} \min ^{-1}\right)$ per gram of dry matter. All of the dry matter of the sample was assumed to possess antioxidant properties.

Pro-oxidant Activity. The pro-oxidant activities were determined using crocin as a radical quencher, according to the methodology described by Manzocco, 
Calligaris and Nicoli, (2002). Crocin was isolated from saffron (Sigma Chemical Co, St. Louis, MO) by methanol extraction after repeated washings with ethyl ether. The crocin solution was diluted with $0.1 \mathrm{M}$ phosphate buffer, $\mathrm{pH} 7.0$ (Sigma Chemical Co, Louis MO) in order to obtain a $1.35 \times 10^{-5} \mathrm{M}$ crocin solution (The absorption coefficient of crocin at $443 \mathrm{~nm}$ is $1.33 \times 10^{5} \mathrm{~mol}^{-1} \mathrm{~cm}^{-1}$ ). The bleaching rate of crocin at $443 \mathrm{~nm}$, in the presence of the sample, was monitored at $40{ }^{\circ} \mathrm{C}$ by a Uvikon 860 (Kontron Instruments, Milan, Italy) spectrophotometer. The reaction was started by the addition of increasing amounts of sample (0-100 $\mu \mathrm{L})$ to $2 \mathrm{~mL}$ of crocin aqueous solution in a $3 \mathrm{~mL}$ capacity cuvette $(1 \mathrm{~cm}$ length). The decrease in absorbance was determined every $30 \mathrm{~s}$ for $10 \mathrm{~min}$. The prooxidant activity was expressed as the decrease in crocin absorbance at $443 \mathrm{~nm}$ after $5 \mathrm{~min}$ of reaction $\left(\Delta \mathrm{OD} 5 \min \mathrm{mg} \mathrm{dm}^{-1}\right)$.

Redox potential. The redox potential measurements of the coffee samples were assessed by a platinum indicating electrode and a $\mathrm{Ag} / \mathrm{AgCl}, \mathrm{Cl}^{-}$sat reference electrode connected with a voltmeter (Crison, mod. 2002, Alella, Spain). Calibration was performed against redox standard solutions having redox potential values of 220 and $465 \mathrm{mV}$ (Reagecon, Shannon, Co. Clare, Ireland) at $25^{\circ} \mathrm{C}$. Electrodes were placed in a $50 \mathrm{~mL}$ 3-neck flask containing a volume of 20 $\mathrm{mL}$ of sample. Prior to analysis, oxygen was removed from the system by nitrogen flushing for $10 \mathrm{~min}$. Data were recorded for at least $20 \mathrm{~min}$ at $25^{\circ} \mathrm{C}$, until a stable potential was reached. A stable potential was arbitrarily defined as a change of less than $1 \mathrm{mV}$ in a 3 min period.

HPLC analysis. HPLC analysis was carried out with an analytical HPLC unit (Varian Pro Star 230), equipped with a Rheodyne injector of $10 \mu \mathrm{L}$ loop and a diode-array detector (Varian Pro Star). A column Alltima C18 (5 $\mu \mathrm{m}$ particle size, $250 \times 4.6 \mathrm{~mm}$ ) was used (Alltech Associates, Inc., Deerfield, IL, USA). The 
mobile phase was $100 \%$ solvent $\mathrm{A}$ (5\% acetic acid in water) for $10 \mathrm{~min}$ and then $90 \%$ solvent $\mathrm{A} / 10 \%$ methanol for the following $40 \mathrm{~min}$ at a flow of $0.7 \mathrm{~mL} / \mathrm{min}$. Pertinent reaction products were identified by retention times with authentic compounds in identical conditions and on-line UV spectra.

Statistical analysis. Each analysis was made in duplicate. Analysis of variance (ANOVA) and a posteriori t-Tukey test with a level of signification of $95 \%$ were applied. Pearson correlations were applied among all the parameters. All statistical analyses were performed using the SPSS v.15.0 software package.

\section{RESULTS AND DISCUSSION}

Absorption at $280 \mathrm{~nm}$ and $420 \mathrm{~nm}$ of $1 \%(\mathrm{w} / \mathrm{v})$ caffeic acid hydroalcoholic solution heated at $90{ }^{\circ} \mathrm{C}$ for increasing time is shown in Table 1. Unheated caffeic acid solution was taken as reference. It can be observed that the absorbance at 280 $\mathrm{nm}$ decreased with the increase of heating time, mainly during the first 4-6 hours. Since caffeic acid is known to absorb at $280 \mathrm{~nm}$ and to decompose upon heating, the decrease of absorbance at this wavelength clearly indicated its linear progressive decomposition $(\mathrm{r}=-0.914, \mathrm{p}<0.001)$. By contrast, the absorbance at $420 \mathrm{~nm}$ increased with heating time $(\mathrm{r}=0.856, \mathrm{p}<0.01)$, indicating a gradual browning of the reacting solution. Absorbance data are in agreement with the changes in $L^{*}, a^{*}$ and $b^{*}$ Hunter parameters (Table 1). In fact, $L^{*}$ parameter (lightness) slightly changed within the first 14 hour-heating but significantly decreased when heat treatment was prolonged up to 24 hours. Parameter a* (red colour) decreased progressively up to 4 hour-heating and then increased reaching the highest value at 24 hours, but in all cases close to zero. On the contrary, the parameter $b^{*}$ (yellow colour) increased progressively showing a significant correlation with the browing increase (Abs 420nm) $(\mathrm{r}=0.908, \mathrm{p}<0.01)$. 
The antioxidant capacity upon heating of the hydroalcoholic solution containing caffeic acid was evaluated by analysing both the chain breaking activity and the redox potential value because different and complementary information can be obtained by their comparison. In fact, the redox potential gives indication on the effective oxidation/reduction efficiency of all the antioxidants present, including the "slow" ones, which can not be detected by kinetic methods (Anese \& Nicoli, 2003).

The evolution of chain-breaking activity and redox potential during heat treatment is shown in Figure 1. It can be observed that after one hour of heating a decrease of chain-breaking activity was produced. A concomitant increase in the redox potential value was detected, indicating that the overall reducing properties of the sample were decreased. Upon further heating, the redox potential decreased $(\mathrm{r}=-$ 0.957, $\mathrm{p}<0.001)$ whilst a partial recovery was detected for chain-breaking activity. However, no significant changes in this property were observed in the case of samples heated for more than 6 hours.

These results clearly show that the oxidative properties of caffeic acid are greatly affected by heat treatments. The complex evolution of both thermodynamic and kinetic properties of the reacting solution indicates that caffeic acid degradation products are characterised by different oxidative state. In particular, the early steps of caffeic acid degradation are likely to be associated to the formation of decomposition products presenting lower antioxidant capacity as compared to the original molecule and/or to the development of novel compounds exerting prooxidant activity. By contrast, the increase in antioxidant activity observed on further heating can be accounted for by the formation of polymers with higher antioxidant activity. However, the possible consumption, in the advanced steps of 
the reaction, of pro-oxidant molecules previously formed could also contribute to explain the recovery in antioxidant properties.

In order to evaluate whether pro-oxidant species are formed during the early steps of caffeic acid decomposition, samples heated for up to 6 hours were assessed for their ability to exert pro-oxidant capacity by quenching a reference antioxidant (Figure 2). It is interesting to note that unheated caffeic acid showed a significant pro-oxidant activity. As known, most antioxidants present in foods (e.g. ascorbic acid, $\alpha$-tocopherols, flavonoids and catechins) are capable of exerting pro-oxidant actions depending on the reaction conditions (Auroma, 1996). Thus, caffeic acid exerts antioxidant activity towards $\mathrm{DPPH} \cdot$ and pro-oxidant activity towards crocin, according to their redox potential values $(229,199$ and $120 \mathrm{mV}$ respectively for DPPH', caffeic acid and crocin) (Anese \& Nicoli, 2003). Figure 2 shows that the pro-oxidant activity of the caffeic acid solution increased after one hour of heat treatment. This result confirms that the increase in redox potential observed in the early steps of the reaction (Figure 1) could be attributed to the formation of novel pro-oxidants. When heating was prolonged, the pro-oxidant activity decreased probably due to the consumption of pro-oxidant molecules which further react to form compounds with stronger antioxidant properties as compared to original caffeic acid (Figures 1-2).

The mechanistic route of caffeic acid decomposition under acid or thermal conditions is a reaction via decarboxilation and ciclysation of vinylcatechol intermediate as described for styrene (Taylor, Keen, \& Eisenbraun, 1977; Rizzi \& Boekley, 1992). In particular, caffeic acid has a proclivity to lose carbon dioxide readily forming nucleophilic p-vinylcatechol which easily beget pro-oxidant cations (Clarke \& Macrae, 1983; Henrich \& Baltes, 1987; Stadler, Welti, Stämpfli \& Fay, 1996). Although p-vinylpyrocatechol cations are extremely susceptible to 
oxidation, resulting in rapid polymerization, it can be inferred that their formation can not be underestimated deeply affecting both the antioxidant status and the reaction pathway.

Caffeic acid polymerisation produces two steroisomers of 2,5-(3',4'dihydroxyphenyl) tetrahydrofuran-3,4-dicarboxylic acid and a range of phenylindan-type stereoisomers (Fulcrand, Cheminat, Brouillard \& Cheynier, 1995; Stadler, Turesky, Muller, Markovic \& Leong-Moergenthaler, 1994; Stadler, Welti, Stämpfli \& Fay, 1996). Structurally these tricyclic dimmers contain two odihydroxy-benzyl moieties, common features found in compounds with good reducing and antioxidant properties (Cuvelier, Richard \& Berset, 1992, Guillot, Malnoë \& Stadler, 1996). Besides, two small compounds with antioxidant activity (catechol, ethylcatechol) are also formed. The formation of phenylindans, catechol and ethylcatechol exerting strong antioxidant properties could give reason of the increase in antioxidant capacity (Figure 2) and the decrease in pro-oxidant activity (Figure 2) observed in the advanced phases of the reaction.

Caffeic acid and its decomposition compounds were analysed by HPLC. Table 2 shows the area results of the seven peaks observed during the experiment. Caffeic acid (peak 2) remains constant until 3-hour heating and then starts decreasing, reaching the lowest value at 24 hours of heat treatment. It can be observed that different compounds are formed whereas caffeic acid is consumed. In samples of unheated and 1-hour heated caffeic acid a peak at 38 min was observed (peak 6). The presence of this peak (38 minutes) could be related to the increase of redox potential and pro-oxidant capacity (Figures 1 and 2), being potentially associated to pro-oxidant molecules such as vinylcatechol formed by decarboxylation of caffeic acid (Clarke \& Macrae, 1983; Henrich \& Baltes, 1987). 
Table 2 shows that three peaks (peaks 4, 5 and 7) with retention time of 36, 37 and 42 min appeared after 2-hour heating of the caffeic acid solution. It must be noted that these peaks significantly increased during heat treatment. Prolonging heating time, a decrease in their area was detected so that a maximum value was observed at 14 hour-heating. According to literature data, these peaks could reasonably be associated to the phenylindan-type stereoisomers previously isolated and identified as the major products of caffeic acid pyrolysis (Stadler, Turesky, Muller, Markovic \& Leong-Moergenthaler, 1994, Stadler, Welti, Stämpfli, \& Fay, 1996). The formation of these antioxidant compounds, also in less extreme thermal conditions, could give reason of the recovery in antioxidant capacity observed after 2-hour heating (Figure 2) (Cuvelier, Richard \& Berset, 1992). Moreover, the found linear significant and positive correlations between each three peaks (4, 5 and 7) and Absorbance at 420nm (0.715, $<<0.05 ; 0.865, \mathrm{p}<0.01$; and $0.739, \mathrm{p}<0.05$, respectively) and with $\mathrm{b}^{*}$ (yellowish) colour parameter $(0.800$, $\mathrm{p}<0.05 ; 0.860, \mathrm{p}<0.01 ;$ and $0.714, \mathrm{p}<0.05$, respectively), and the negative correlations between peak 6 and both polymers markers $(-0.728, p<0.05$ with Abs420nm; and $-0.796, \mathrm{p}<0.05$ with $\mathrm{b}^{*}$ ) are in agreement with this route of polymerisation. The evolution of peaks 4,5 and 7 indicates that, as the reaction proceeds, phenylindan-type stereoisomers are formed to a minor extent or are consumed in the reaction pathway. This hypothesis is supported by the occurrence of two additional peaks in the advanced steps of the reaction. In particular, peak 1 and peak 3 were respectively observed starting from 3- and 14-hour heating. It must be noted that peak 1 was identified as related to catechol formation. Both peaks were very and significant negative correlated with redox potential $(-0.926$, $\mathrm{p}<0.001$ for peak 1 and $-0.907, \mathrm{p}<0.01$ for peak 3 ). Taking into account these results, it can be inferred that the increase in antioxidant activity due to the 
formation of phenylindans and catechols could be counterbalanced by the consumption of caffeic acid, thus leading to slight changes in antioxidant properties in the advanced steps of the reaction (Figure 1).

\section{CONCLUSIONS}

Results obtained in this study clearly showed that caffeic acid, which is widely recognised to exert antioxidant properties, may also act as pro-oxidant. In addition, upon thermal treatment, it was shown to produce decomposition products with significant pro-oxidant activity. In fact, highly reactive cations are generated in the early phases of caffeic acid degradation, deeply affecting both the oxidative status and the reaction pathway of the system. However, a partial recovery in antioxidant activity was observed maybe due to cation coupling and polymerisation reactions.

These results appear of considerable interest as regards the implications of food processing operations and, in this case, the heat maintenance of coffee brews in thermos, promoting phenol polymerisation and/or degradation. The latter may actually invert dietary polyphenols from antioxidants to pro-oxidants, consequently favouring lipid peroxidation not only in food but also in vivo during digestion.

It can be concluded that both nature and extent of the reactions occurring in phenol-containing foods and also other factors such as reaction media, matrix and so on, can greatly influence the fate of polyphenols. The marked fluctuation in their oxidative properties upon heat maintenance indicates that further research is needed to determine those technological conditions able to minimise the development of pro-oxidant activity and promote a gain in the antioxidant capacity. Moreover, this raises the question if the increase in food nutritional 
value is really achievable through the addition of polyphenols. Although there is no direct and compelling evidence that the common custom of fortification with polyphenols is related to positive effects on the human health, a negative synergism on antioxidant activity among phenols in food fortification has been reported (Pinelo, Manzocco, Nunez \& Nicoli, 2004). However, there is considerable circumstantial evidence to suggest that caution should be used in interpreting enthusiastic data relevant to the antioxidant properties of polyphenols.

\section{ACKNOWLEDGEMENTS}

We thank the Ministerio de Ciencia y Tecnología Español for the grant given to S. Andueza.

\section{REFERENCES}

Auroma, O. I. (1996). Assessment of potential pro-oxidant and antioxidant actions. Journal of the American Oil Chemists' Society, 73, 1617-1625.

Anese, M., \& Nicoli, M. C. (2003). Antioxidant Properties of ready-to-drink coffee brews. Journal of Agricultural and Food Chemistry, 51, 942-946.

Brand-Wiliams, W., Cuvelier, M. E., \& Berset, C. (1995). Use of a free radical method to evaluate antioxidant activity. Lebensmittel Wissenschaft und Technologie, 28, 25-30.

Britt, P. F., Buchanan, A. C., Thomas, K. B., \& Lee, S. K. (1995). Pyrolysis mechanisms of lignin: surface-immobilized model compound investigation of acid-catalyzed and free-radical reaction pathways. Journal of Analytical and Applied Pyrolysis, 33, 1-19.

Clarke, R. J., \& Macrae, R. (1983). Coffee Volume 1: Chemistry. London: Applied Science. 
Clifford, M. N. (1999). Chlorogenic acids and other cinnamates: nature, occurrence and dietary burden. Journal of the Science of Food and Agriculture, 79, 362-72.

Clydesdale, F. M. (1978). Colorimetry methodology and applications. Critical Reviews in Food Science and Nutrition, 10, 243-301.

Cuvelier, M. E., Richard, H., \& Berset, C. (1992). Comparison of antioxidative activity of some acid-phenols: structure-activity relationship. Bioscience Biotechnology and Biochemistry, 56, 324-325.

Fulcrand, H., Cheminat, A., Brouillard, R., \& Cheynier, V. (1995). Characterisation of caffeic acid oxidation products. In R. Brouillard, M. Jay, \& A. Scalbert, Polyphenols 94. XVIIe Journeés Internationales Groupe Polyphenols, (pp.157-158). Paris: INRA.

Fulcrand, H., Benabdeljalil, C., Rigaud, J., Cheynier, V., \& Mountounet, M. (1998). A new class of wine pigments generated by reaction between pyruvic acid and grape anthocyanins. Phytochemistry, 47, 1401-1407.

Guillot, F.L., Malnoë, A. and Stadler, R.H. (1996). Antioxidant properties of nover tetraoxygenated phenylindan isomers formed during thermal decomposition of caffeic acid. Journal of Agricultural and Food Chemistry, 44 (9), 2503-2510.

Halliwell, B. (2003). Oxidative stress in cell culture: an under-appreciated problem?. FEBS Letters, 540, 3-6.

Henrich, L., \& Baltes, W. (1987) Vorkommen von Phenolen in Kaffee Melanoidine. Zeitschrift für Lebensmittel-Untersuchung und-Forschung, 185, 366-370. 
Kanner, J., \& Lapidot, T. (2001). The stomach as a bioreactor: dietary lipid peroxidation in the gastric fluid and the effects of plant-derived antioxidants. Free Radical Biology and Medicine, 31, 1388-1395.

Kobayashi, S. \& Higashimura, H. (2003). Oxidative polymerisation of phenol revisited. Progress in Polymer Science, 28, 1015-1058.

Manzocco, L., Anese, M., \& Nicoli, M. C. (1998). Antioxidant properties of tea extracts as affected by processing. Lebensmittel-Wissenschaft undTechnologie, 31, 694-698.

Manzocco, L., Calligaris, S., \& Nicoli, M. C. (2002). Assessment of pro-oxidant activity of foods by kinetic analysis of crocin bleaching. Journal of Agricultural and Food Chemistry, 50, 2767-2771.

Meskin, M.S., Bidlack, W.R., Davies, A.J., Lewis, D.S. and Randolph, R.K. (2004). Phytochemicals. Mechanisms of action. CRC Press, Boca Raton, Florida.

Nicoli, M. C., Calligaris, S., \& Manzocco, L. (2000). Effect of enzymatic and chemical oxidation on the antioxidant capacity of catechin model systems and apple derivatives. Journal of Agricultural and Food Chemistry, 48, 4576-4580.

Pinelo, M., Manzocco, L., Nunez,M. J., \& Nicoli, M. C. (2004). Interaction among phenols in food fortification: negative synergism on antioxidant capacity. Journal of Agricultural and Food Chemistry, 52, 1177-1180.

Rice-Evans, C. A., Miller, N. J., \& Paganga, G. (1996). Structure-antioxidant activity relationships of flavonoids and phenolic acids. Free Radical Biology and Medicine, 20, 933-956.

Rizzi, G. P., \& Boekley, L. J. (1992). Observation of ether linked phenolic products during thermal degradation of ferulic acid in the presence of alcohols. Journal of Agricultural and Food Chemistry, 40, 1666-1670. 
Shahidi, F. and Naczk, M. (2004). Phenolics in food and nutraceuticals. CRC Press, Boca Raton, Florida.

Stadler, R. H. (2001). The use of chemical markers and model studies to assess the in vitro pro- and antioxidative properties of methylxanthine-rich beverages. Food Reviews International, 17 (4), 385-418.

Stadler, R. H., Turesky, R. J., Muller, O., Markovic, J., \& Leong-Moergenthaler, P. M. (1994). The inhibitory effects of coffee on radical-mediated oxidation and mutagenicity. Mutation Research, 308, 177-190.

Stadler, R. H., Welti, D. H., Stämpfli, A. A., \& Fay, L. B. (1996). Thermal decomposition of caffeic acid in model systems: identification of novel tetraoxygenated phenylindan isomers and their stability in aqueous solution. Journal of Agricultural and Food Chemistry, 44, 898-905.

Taylor, A. R., Keen, G. W., \& Eisenbraun, E. J. (1977). Cyclodimerization of styrene. Journal of Organic Chemistry, 42, 3477-3480. 


\section{FIGURE CAPTIONS}

Figure 1. Chain-breaking activity and redox potential of a $1 \% \mathrm{w} / \mathrm{v}$ caffeic acid hydroalcoholic solution during heating at $90^{\circ} \mathrm{C}$.

Figure 2. Pro-oxidant capacity of a $1 \% \mathrm{w} / \mathrm{v}$ caffeic acid hydroalcoholic solution during heating at $90^{\circ} \mathrm{C}$. 
Table 1. Absorbance and colour of samples of a $1 \% \mathrm{w} / \mathrm{v}$ caffeic acid hydroalcoholic solution heated at $90^{\circ} \mathrm{C}$.

\begin{tabular}{cccccc}
\hline $\begin{array}{c}\text { Time } \\
\text { (hours) }\end{array}$ & $\begin{array}{c}\text { Abs 280 nm } \\
(\mathbf{n = 4})\end{array}$ & $\begin{array}{c}\text { Abs 420 nm } \\
(\mathbf{n = 4})\end{array}$ & $\begin{array}{c}\mathbf{L}^{*} \\
\mathbf{( n = 4 )}\end{array}$ & $\begin{array}{c}\mathbf{a}^{*} \\
(\mathbf{n}=\mathbf{4})\end{array}$ & $\begin{array}{c}\mathbf{b}^{*} \\
(\mathbf{n}=\mathbf{4})\end{array}$ \\
\hline $\mathbf{0}$ & $0.703 \pm 0.001^{\mathrm{h}}$ & $0.000 \pm 0.000^{\mathrm{a}}$ & $53.89 \pm 0.84^{\mathrm{d}}$ & $1.79 \pm 0.05^{\mathrm{g}}$ & $2.37 \pm 0.26^{\mathrm{a}}$ \\
$\mathbf{1}$ & $0.659 \pm 0.001^{\mathrm{g}}$ & $0.039 \pm 0.019^{\mathrm{b}}$ & $52.23 \pm 0.26^{\mathrm{b}}$ & $1.48 \pm 0.07^{\mathrm{e}}$ & $3.27 \pm 0.32^{\mathrm{b}}$ \\
$\mathbf{2}$ & $0.597 \pm 0.001^{\mathrm{e}}$ & $0.750 \pm 0.014^{\mathrm{c}}$ & $55.04 \pm 0.20^{\mathrm{e}}$ & $-0.29 \pm 0.14^{\mathrm{d}}$ & $10.23 \pm 0.57^{\mathrm{c}}$ \\
$\mathbf{3}$ & $0.622 \pm 0.001^{\mathrm{f}}$ & $1.380 \pm 0.010^{\mathrm{d}}$ & $54.33 \pm 0.38^{\mathrm{d}}$ & $-2.19 \pm 0.05^{\mathrm{b}}$ & $19.95 \pm 0.28^{\mathrm{e}}$ \\
$\mathbf{4}$ & $0.540 \pm 0.001^{\mathrm{d}}$ & $1.894 \pm 0.006^{\mathrm{f}}$ & $54.31 \pm 0.27^{\mathrm{d}}$ & $-3.04 \pm 0.02^{\mathrm{a}}$ & $24.25 \pm 0.52^{\mathrm{g}}$ \\
$\mathbf{6}$ & $0.438 \pm 0.001^{\mathrm{c}}$ & $1.588 \pm 0.005^{\mathrm{e}}$ & $54.27 \pm 0.28^{\mathrm{d}}$ & $-2.21 \pm 0.02^{\mathrm{b}}$ & $20.51 \pm 0.12^{\mathrm{e}}$ \\
$\mathbf{1 4}$ & $0.434 \pm 0.001^{\mathrm{b}}$ & $2.160 \pm 0.018^{\mathrm{g}}$ & $52.85 \pm 0.03^{\mathrm{c}}$ & $-1.26 \pm 0.03^{\mathrm{c}}$ & $18.49 \pm 0.08^{\mathrm{d}}$ \\
$\mathbf{2 4}$ & $0.305 \pm 0.001^{\mathrm{a}}$ & $2.893 \pm 0.010^{\mathrm{h}}$ & $45.32 \pm 0.24^{\mathrm{a}}$ & $3.00 \pm 0.22^{\mathrm{f}}$ & $22.78 \pm 0.20^{\mathrm{f}}$ \\
\hline \hline
\end{tabular}

Results are shown as means \pm standard deviations. In each column, different superscripts (letters a, $\mathrm{b}, \mathrm{c})$ indicate significant difference $(\mathrm{p}<0.05)$ among samples. The same letter indicates that there is no significant difference among samples in this parameter. 
Table 2. Compounds determined by HPLC (Results shown as area).

\begin{tabular}{|c|c|c|c|c|c|c|c|}
\hline $\begin{array}{l}\text { Time } \\
\text { (hours) }\end{array}$ & $\begin{array}{c}\text { Peak 1 } \\
\text { Catechol } \\
\text { Rt=8 min }\end{array}$ & $\begin{array}{c}\text { Peak } 2 \\
\text { Caffeic Acid } \\
\text { Rt=20min }\end{array}$ & $\begin{array}{c}\text { Peak } 3 \\
\mathrm{Rt}=33 \mathrm{~min}\end{array}$ & $\begin{array}{c}\text { Peak } 4 \\
\mathrm{Rt}=36 \mathrm{~min}\end{array}$ & $\begin{array}{c}\text { Peak } 5 \\
\mathrm{Rt}=37 \mathrm{~min}\end{array}$ & $\begin{array}{c}\text { Peak } 6 \\
\mathrm{Rt}=38 \mathrm{~min}\end{array}$ & $\begin{array}{c}\text { Peak } 7 \\
\mathrm{Rt}=42 \text { min }\end{array}$ \\
\hline 0 & n.d. & $371 \pm 10^{\mathrm{cd}}$ & n.d. & n.d. & n.d. & $11.0 \pm 0.4^{\mathrm{a}}$ & n.d. \\
\hline 1 & n.d. & $409 \pm 10^{\mathrm{d}}$ & n.d. & $4.6 \pm 0.1^{\mathrm{a}}$ & n.d. & $24.0 \pm 0.2^{\mathrm{b}}$ & n.d. \\
\hline 2 & n.d. & $370 \pm 40^{\mathrm{cd}}$ & n.d. & $15.0 \pm 1.5^{\mathrm{b}}$ & $20.0 \pm 0.1^{b}$ & n.d. & $5.0 \pm 0.1^{\mathrm{a}}$ \\
\hline 3 & $0.3 \pm 0.0^{\mathrm{a}}$ & $407 \pm 66^{\mathrm{cd}}$ & n.d. & $33.0 \pm 1.3^{\mathrm{d}}$ & $17.0 \pm 0.2^{\mathrm{a}}$ & n.d. & $5.0 \pm 0.2^{\mathrm{a}}$ \\
\hline 4 & $0.8 \pm 0.0^{\mathrm{b}}$ & $292 \pm 10^{\mathrm{b}}$ & n.d. & $44.0 \pm 1.5^{\mathrm{e}}$ & $21.0 \pm 0.2^{\mathrm{c}}$ & n.d. & $7.0 \pm 0.1^{\mathrm{c}}$ \\
\hline 6 & $1.0 \pm 0.1^{\mathrm{c}}$ & $333 \pm 37^{\mathrm{ab}}$ & n.d. & $54.0 \pm 1.2^{\mathrm{f}}$ & $24.0 \pm 0.1^{\mathrm{d}}$ & n.d. & $9.0 \pm 0.2^{\mathrm{d}}$ \\
\hline 14 & $4.6 \pm 0.1^{\mathrm{d}}$ & $273 \pm 30^{\mathrm{ab}}$ & $0.2 \pm 0.0^{\mathrm{a}}$ & $62.0 \pm 2.0^{\mathrm{g}}$ & $28.0 \pm 0.1^{\mathrm{e}}$ & n.d. & $14.0 \pm 0.3^{\mathrm{e}}$ \\
\hline 24 & $4.5 \pm 0.0^{\mathrm{d}}$ & $236 \pm 10^{\mathrm{a}}$ & $0.4 \pm 0.0^{\mathrm{b}}$ & $26.0 \pm 2.0^{\mathrm{c}}$ & $24.0 \pm 0.2^{\mathrm{d}}$ & n.d. & $6.0 \pm 0.1^{\mathrm{b}}$ \\
\hline
\end{tabular}

Results are shown as means \pm standard deviations. In each row, different letters indicate significant difference $(p<0.05)$ among different times of heat treatment.

The peak 3 could be the ethylcatechol.

The peaks 4, 5, 7 could be phenylindans.

The peak 6 could be the vinylcatechol.

n.d. Not detectable 
Figure 1.

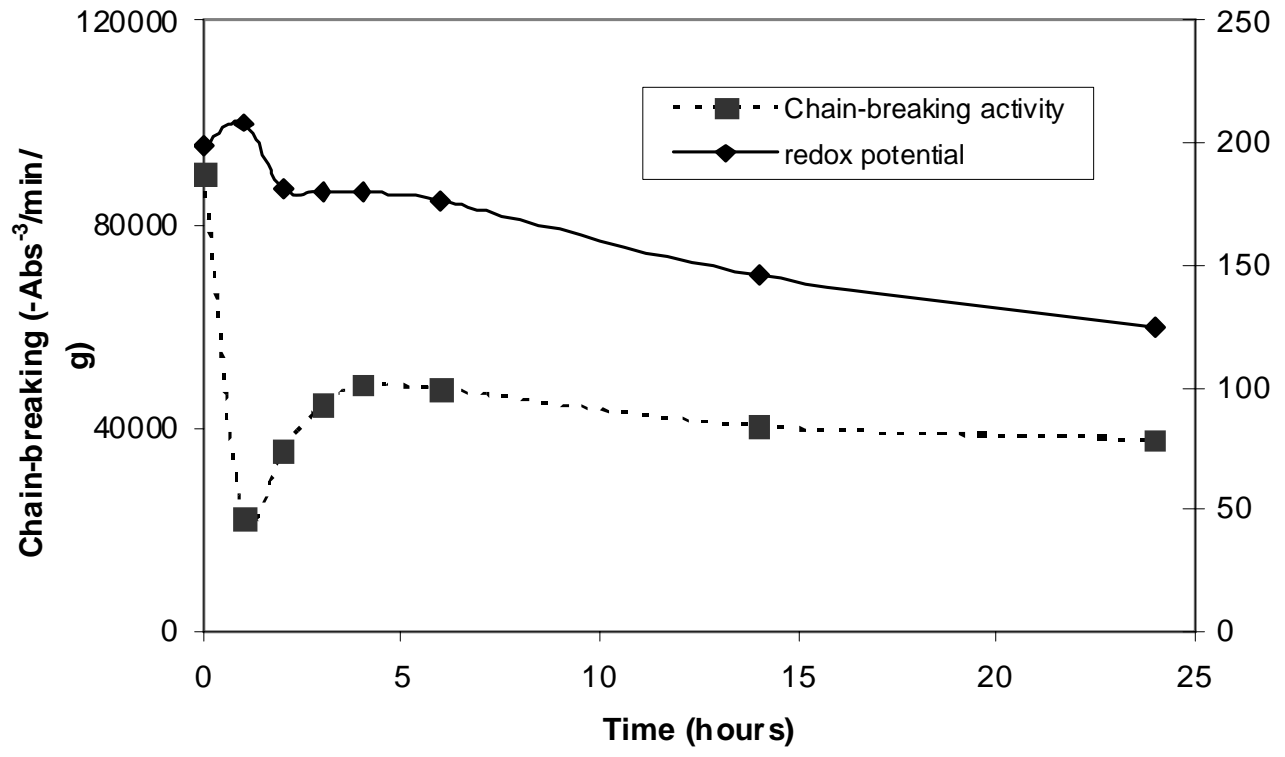

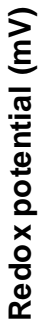


Figure 2.

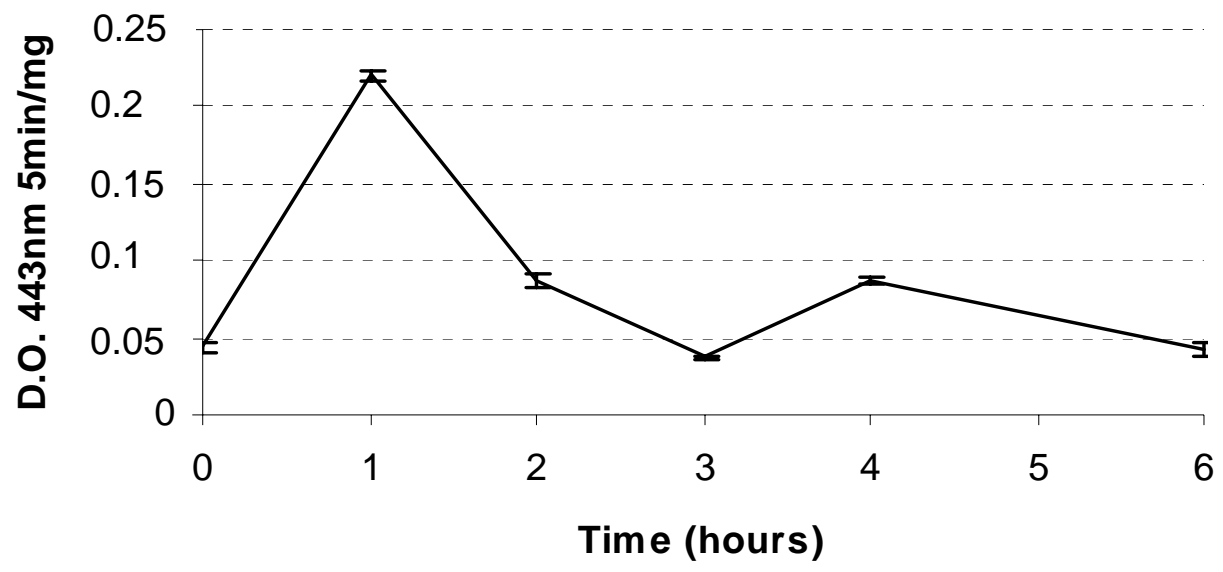

